\title{
A prospective study of the muscle strength and reaction time of the quadriceps, hamstring, and gastrocnemius muscles in patients with plantar fasciitis
}

Jin Hyuck Lee ${ }^{1}$, Hae Woon Jung ${ }^{2}$ and Woo Young Jang ${ }^{1,3^{*}}$ (D)

\begin{abstract}
Background: Muscle weakness is an important etiological factor in plantar fasciitis (PF), but available data on the role of the quadriceps, hamstring, and gastrocnemius (GCM) muscles are limited. The aim of this study was to compare the strength and reaction time of the quadriceps, hamstring, and GCM muscles and foot pressure between patients with PF and normal controls.
\end{abstract}

Methods: A total of 21 PF patients and 21 normal controls were enrolled. Muscle strength was measured by the peak torque per body weight $\left(\mathrm{Nmkg}^{-1} \times 100\right)$. Muscle reaction time was evaluated by the acceleration time (AT, milliseconds). Foot pressure and posture were assessed by pedobarography [valgus/varus index (W index), \%].

Results: The strength of the quadriceps was significantly lower in the affected ankles of the PF group than in the control group $(p=0.005)$. The AT of the quadriceps and hamstring muscles was significantly increased in the affected ankles of the PF group than in the control group (quadriceps: $p=0.012$, hamstring: $p=0.001$ ), while the AT of the GCM muscle was significantly decreased $(p=0.009)$ and significantly correlated negatively with quadriceps muscle strength $(r=-.598, p=0.004)$ and AT $(r=-.472, p=0.031)$. Forefoot $(p=0.001)$ and hindfoot $(p=0.000)$ pressure were significantly greater, with the $\mathrm{W}$ index showing hindfoot valgus, in the affected ankles in the PF group compared to the control group ( $p=0.039$ ).

Conclusions: This study demonstrated weakness and delayed reaction time of the quadriceps and hamstring muscles, with a rapid reaction time of the GCM muscle, in patients with PF.

Clinical relevance: Clinicians and therapists should assess the function of the quadriceps and hamstring muscles when planning the management of PF patients without muscle tightness.

Keywords: Plantar fasciitis, Muscle reaction time, Foot pressure, Pedobarography, Gastrocnemius

\footnotetext{
* Correspondence: opmanse@gmail.com

'Department of Sports Medical Center, Korea University College of Medicine, Anam Hospital, Seoul, Republic of Korea

${ }^{3}$ Department of Orthopedic Surgery, College of Medicine, Korea University,

73, Inchon-ro, Seongbuk-gu, Seoul 02841, Republic of Korea

Full list of author information is available at the end of the article
}

C C The Author(s). 2020 Open Access This article is licensed under a Creative Commons Attribution 4.0 International License, which permits use, sharing, adaptation, distribution and reproduction in any medium or format, as long as you give appropriate credit to the original author(s) and the source, provide a link to the Creative Commons licence, and indicate if changes were made. The images or other third party material in this article are included in the article's Creative Commons licence, unless indicated otherwise in a credit line to the material. If material is not included in the article's Creative Commons licence and your intended use is not permitted by statutory regulation or exceeds the permitted use, you will need to obtain permission directly from the copyright holder. To view a copy of this licence, visit http://creativecommons.org/licenses/by/4.0/. The Creative Commons Public Domain Dedication waiver (http://creativecommons.org/publicdomain/zero/1.0/) applies to the data made available in this article, unless otherwise stated in a credit line to the data. 


\section{Background}

Plantar fasciitis (PF) is one of the most common problems associated with foot pain. The causes of PF include excessive physical activity, [1] obesity, [2] age, [3] prolonged standing, [2] altered biomechanics, [4, 5] limited ankle dorsiflexion with foot postures such as pes cavus and pes planus, [6] and hamstring tightness [7]. Among these, limited ankle dorsiflexion is caused by tightness of the gastrocnemius (GCM), which may increase the stress on the plantar fascia because it affects the alignment of the calcaneal bones [8]. Hamstring tightness may induce prolonged forefoot loading, that can result in increased repetitive stress on the plantar fascia [7, 9]. Therefore, most therapists have focused on restoring the flexibility of the posterior muscles, such as the GCM and hamstring muscles in PF patients.

Weakness of the GCM [5] and proximal muscles, $[5,10]$ such as the gluteal and tensor fasciae latae muscles, in patients with PF have been reported, which may impact the plantar fascia load distribution. Recently, a systematic review reported that intrinsic muscle strength is associated with symptoms of PF [11]. Furthermore, a recent study by Lee et al., [5] reported that increased foot pressure in patients with PF may be associated with weakness of the GCM and hip muscles. Therefore, muscle weakness may be an important etiological factor in PF. To date, however, no study has investigated the strength and reaction time of proximal muscles, such as the hamstring and quadriceps muscles, in patients with PF. These muscles are known to play a vital role in the alteration of lower extremity biomechanics [12-15] and may contribute to increased plantar fascia load.

The purpose of this study was to analyze the differences in the strength and reaction time of the quadriceps, hamstring, and GCM muscles as well as foot pressure and posture, between patients with PF and normal controls. We hypothesized that the quadriceps, hamstring, and GCM muscles of PF patients would show decreased strength and delayed reaction time, and these patients would have increased foot pressure compared to normal controls.

\section{Methods}

\section{Participants}

This study was approved by our institutional review board. All study participants provided written informed consent, and the rights of the subjects were protected. This study is a prospective, investigator-initiated trial. All data were managed in Excel files by a blinded author, and statistical analyses were done by a statistician. This prospective casecontrol study enrolled 112 patients with foot pain at our institute between July 2018 and November 2019. Physical examinations and evaluations of all images were independently performed by two experienced surgeons. Any disagreements on any diagnoses of PF were resolved by consensus. In this study, the inclusion criteria were PF patients with normal foot posture in terms of naviculocuboid overlap and talonavicular coverage angle on plain radiographs, without tightness of the GCM or hamstring muscles. We excluded 91 patients for the following reasons (Fig. 1): pain in both feet, metatarsalgia, Morton neuroma, calcaneal spur, pes cavus and pes planus, and tightness of the GCM and hamstring muscles in the Silfverskiold and popliteal angle tests, respectively. We also excluded patients who had received a steroid injection within 6 months or had undergone knee surgery within 1 year. Of the 112 patients, 91 were excluded; therefore, 21 patients were finally enrolled. The 21 normal control subjects selected from our database of volunteers had no history of lower extremity injury symptoms within 1 year and agreed to participate in the study.

\section{Assessment of isokinetic muscle performances Muscle strength of the quadriceps and hamstring}

Isokinetic knee extension/flexion strength (concentric/ concentric mode, $\mathrm{Nmkg}^{-1} \times 100$, Biodex Medical Systems, Shirley, NY) was measured in the sitting position with $90^{\circ}$ flexion of the hips and knee joints on a dynamometer (Fig. 2a). Flexion and extension strength were considered to represent hamstring and quadriceps strength, respectively. Each test consisted of 5 repetitions of flexion/extension $\left(\mathrm{ROM}, 90^{\circ}\right.$ to $0^{\circ}$ ) for each leg at $60^{\circ} / \mathrm{s}$.

\section{Muscle strength of the GCM}

Isokinetic GCM strength (concentric mode, $\mathrm{Nmkg}^{-1} \times$ 100) was measured in a semi-seated position with $20^{\circ}$ of knee flexion [16] on a dynamometer (Fig. 2b), and 5 repetitions of plantar flexion for each leg at $30^{\circ} / \mathrm{s}$.

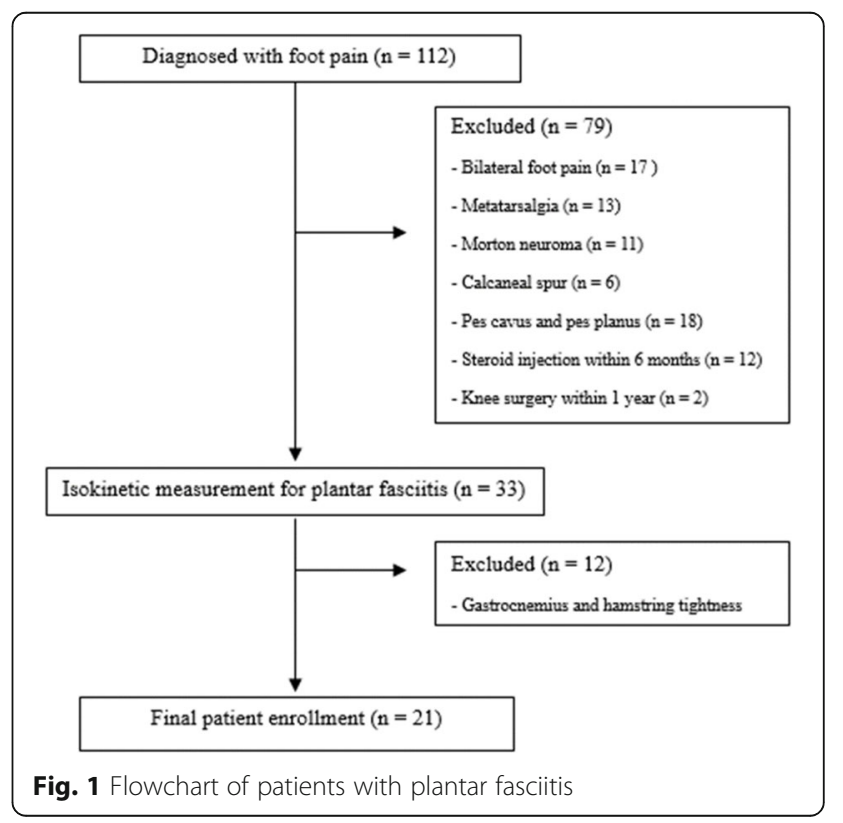




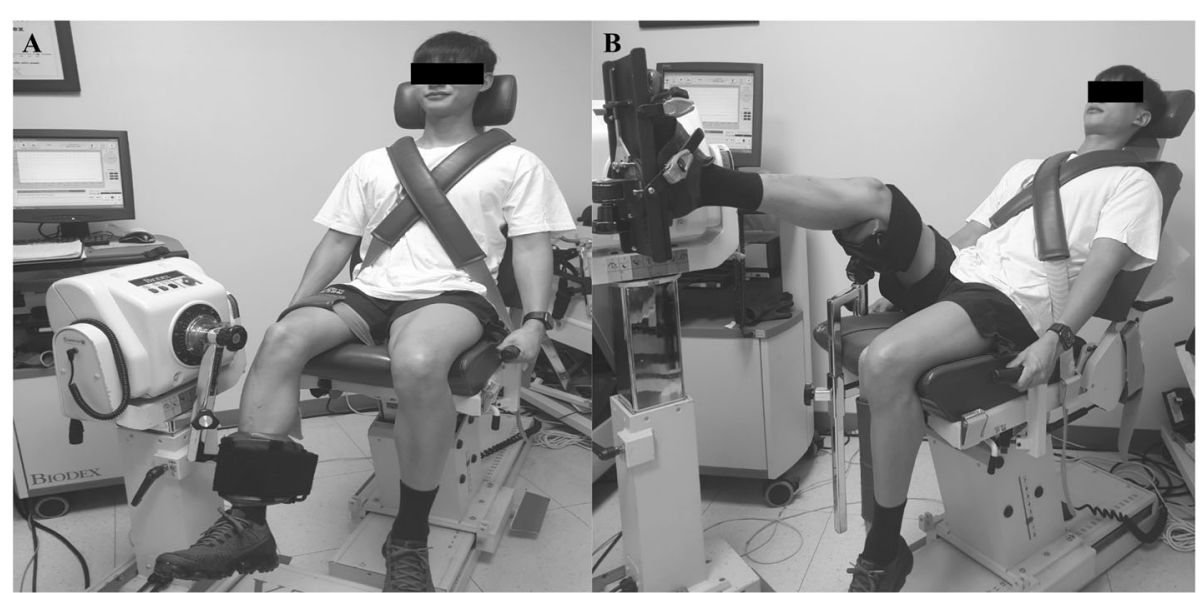

Fig. 2 Measurement of the strength and reaction time of the quadriceps, hamstring (a), and gastrocnemius (b) muscles

Assessment of the muscle reaction time (acceleration time) Muscle reaction time was measured by the acceleration time (AT) during isokinetic strength testing. Muscle reaction time was defined as the time (ms) required to attain the pre-set angular velocity $\left(60^{\circ} / \mathrm{s}\right.$ for the knee joint and $30 \%$ for the ankle joint) during maximal muscle contraction. Lower AT values signify a rapid muscle reaction ability [17-19]. The AT was calculated automatically using the Biodex advantage software.

\section{Assessment of the foot pressure and posture}

Foot pressure was measured by pedobarography [5, 20, 21] (Tekscan, Massachusetts) during a 2-m walk and recorded at $50 \mathrm{~Hz}$. Based on a previous study, [21] the peak pressure and pressure-time integral were calculated for each of the 5 segments of the foot (Fig. 3): the medial forefoot (MFF), lateral forefoot (LFF), medial midfoot (MMF), lateral midfoot (LMF), and heel. These data were processed to yield the valgus/varus index (VV index, \%), which is defined as $((\mathrm{MMF}+\mathrm{MFF}) \quad-\quad(\mathrm{LMF}+\mathrm{LFF})) /(\mathrm{MMF}+\mathrm{MFF}+\mathrm{LFF}+$ LMF), with plus (+) and minus (-) values of the VV index indicating hindfoot valgus and varus, respectively [21]. The same peak pressure and VV index assessment processes were used for the normal controls.

\section{Statistical analysis}

The sample size calculation for this study was based on a previous study of muscle strength in patients with lower extremity injuries, $[19,22]$ and a muscle strength difference $>10 \%$ between the groups was considered significant. To determine the sample size, we conducted an a priori power analysis, with an alpha level of 0.05 , and a power of 0.8. Effect size (Cohen's d: 1.00) was calculated using the mean and standard deviation from the results of a pilot study involving 5 ankles in each group; 17 ankles in each group were required to adequately identify a clinically meaningful difference of $>10 \%$ in muscle strength between the groups. The power necessary to detect differences in muscle strength was 0.813 .

The Student's $t$-test was used to compare the strength and reaction time of the quadriceps, hamstring, and GCM muscles, and the foot pressure and posture between patients with PF and normal controls. To determine whether a continuous variable followed a normal distribution, the Shapiro test was used. Correlations between the strength and reaction time of the quadriceps, hamstring, and GCM muscles were assessed using Pearson's coefficient of correlation. Data were analyzed using SPSS software version 17.0 (SPSS Inc., Chicago, IL, USA). A value of $p<0.05$ was considered statistically significant.

\section{Results}

Table 1 shows the demographic data of the PF patients and normal controls. There were no differences in sex, age, height, weight, or sports and activity levels [23] (high level was defined as participation in competitive sports such as basketball, volleyball, football, and soccer) between the two groups.

\section{Isokinetic strength}

The strength of the quadriceps, but not the hamstring or GCM $(p>0.05$, Table 2), was significantly decreased in the affected ankles of patients with PF compared with those of normal controls ( $115 \pm 34.7$ vs. $144 \pm 26.1$, respectively; $p=0.005$, Table 2 ).

\section{Muscle reaction time (AT)}

The AT of the hamstring and quadriceps muscles was significantly greater in the affected ankles of the PF group than in those of the control group (hamstring: $77 \pm 21.9$ vs. $56 \pm 15.6, p=0.001$, quadriceps: $64 \pm 25.2$ vs. $48 \pm 14.4, p=0.012$, Table 2 ), whereas the AT of the GCM muscle was significantly lower in the PF patients than in the normal controls $(30 \pm 11.4$ vs. $41 \pm 14.4, p=$ 0.009, Table 2). 


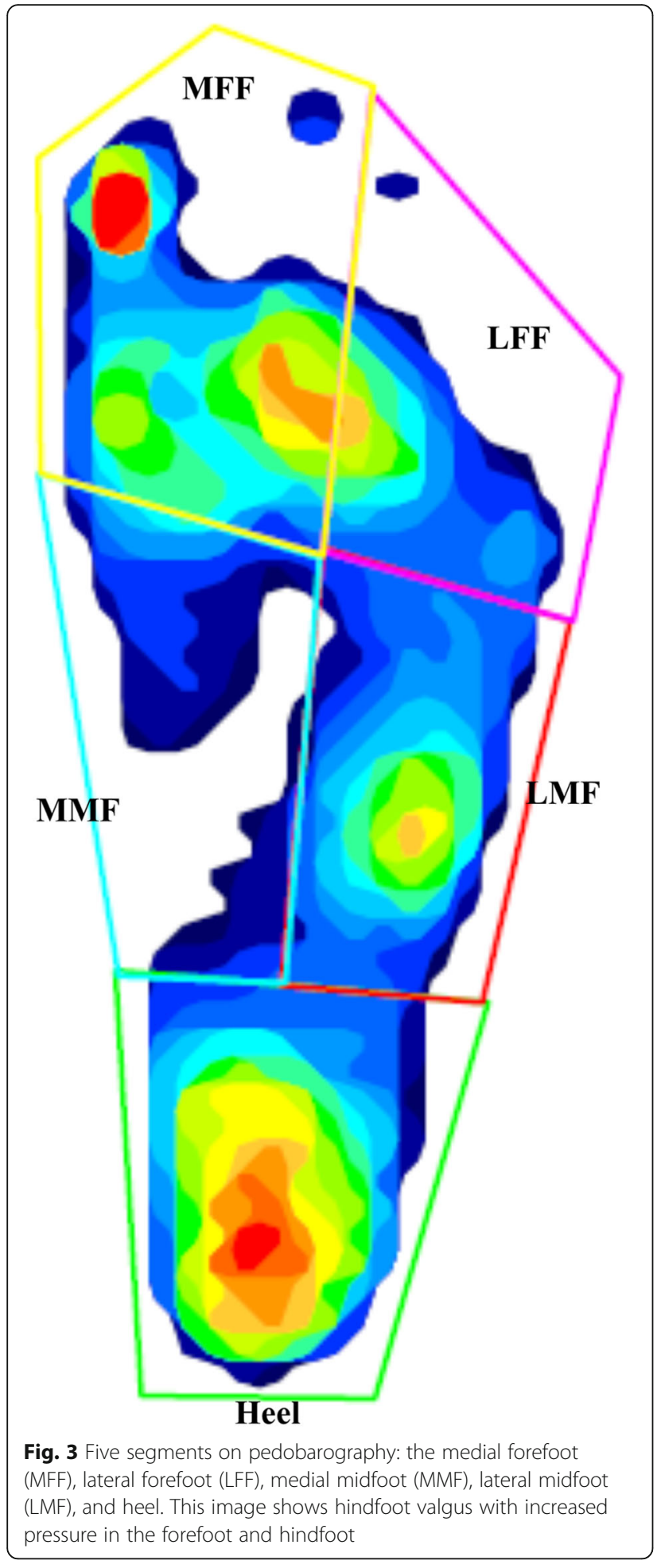

Correlations between the strength and reaction time of the quadriceps, hamstring, and GCM muscles

The strength of the GCM muscle in the affected ankles showed a significant positive correlation with the strength of the hamstring muscle $(\mathrm{r}=.634, p=.002$, Table 3$)$, but not with the quadriceps muscles $(p>0.05$,
Table 3). The AT of the GCM muscle in the affected ankles showed a significant negative correlation with the strength $(\mathrm{r}=-.598, p=.004$, Table 3$)$ and AT $(\mathrm{r}=-.472$, $p=.031$, Table 3 ) of the quadriceps muscle, but not with the hamstring muscle $(p>0.05$, Table 3$)$.

\section{Foot pressure and posture (VV index)}

Forefoot and hindfoot pressure were significantly greater in the affected ankles of patients with PF than in those of normal controls (forefoot: $70 \pm 27.7$ vs. $46 \pm 15.7, p=$ 0.001 , heel: $65 \pm 22.8$ vs. $36 \pm 15.2$, respectively; $p=$ 0.000 , Table 2). The VV index values revealed a higher incidence of hindfoot valgus in the affected ankles of patients with PF compared with those of normal controls $(+0.2 \pm 0.3$ vs. $0 \pm 0.2$, respectively; $p=0.039$, Table 2$)$.

In the unaffected ankles, there were no significant differences in the strength and reaction time of the quadriceps, hamstring, and GCM muscles, nor the foot pressure and posture between the PF group and the control group $(p>0.05$, Table 2$)$.

\section{Discussion}

The most important finding of this study was that quadriceps weakness, delayed reaction time of the hamstring and quadriceps muscles, and rapid reaction time of the GCM muscle can all be demonstrated in the affected ankles of PF patients. The reaction time of the GCM muscle also had a significant negative correlation with the strength and reaction time of the quadriceps muscle. Furthermore, foot pressure at the forefoot and hindfoot significantly increased, and the affected ankles of patients with PF had a higher incidence of hindfoot valgus than those of normal controls.

Weakness of the GCM in patients with PF has been reported [5, 24]. However, these studies investigated PF patients with concurrent tightness of the GCM muscle. Therefore, previous studies were limited because muscle length directly affects muscle strength [25]. However, In this study, PF patients without muscle tightness had weakness of the quadriceps muscle, with no significant difference in the strength of the hamstring and GCM muscles between the groups. Although the reason for these results is unclear, it may be explained by the use of compensatory movement strategies to reduce foot pain. During the gait cycle, [26] foot posture changes from supination to pronation during the change in phase from heel strike to weight acceptance. In patients with PF, foot pain may be due to a stretched plantar fascia in the pronated foot [26]. As a result, patients may use compensatory movement strategies, such as rapid hip flexion to reduce foot pain. In the weight acceptance phase, the quadriceps, hamstring, and GCM muscles, (especially the quadriceps), are highly active in stabilizing the hip and knee joints against gravity and weight [13, 14, 25]. 
Table 1 Demographic data in enrolled patients with plantar fasciitis and normal controls

\begin{tabular}{|c|c|c|c|}
\hline & $\begin{array}{l}\text { PF patients group } \\
(n=21)\end{array}$ & $\begin{array}{l}\text { Normal control group } \\
(n=21)\end{array}$ & $p$-value \\
\hline Sex (male/female) & $10 / 11$ & $13 / 8$ & 0.365 \\
\hline Age (years) ${ }^{a}$ & $53 \pm 4$ & $51 \pm 7$ & 0.342 \\
\hline Height $(\mathrm{cm})^{a}$ & $168 \pm 3$ & $166 \pm 6$ & 0.697 \\
\hline Weight (kg) ${ }^{\text {a }}$ & $66 \pm 7$ & $68 \pm 4$ & 0.778 \\
\hline Sports and activity, n (low:high) & $18: 3$ & $16: 5$ & 0.401 \\
\hline
\end{tabular}

Abbreviations: PF plantar fasciitis

${ }^{\text {a }}$ The values are expressed as mean \pm standard deviation

However, in PF patients, the function of the quadriceps may be gradually reduced by insufficient weight transfer due to such compensatory strategies, thereby resulting in quadriceps muscle weakness. Another possible explanation is overuse of the hip flexion movement performed to reduce foot pain caused by a stretched plantar fascia. The quadriceps muscle is a hip flexor, and weakness in this muscle may result from its overuse [27, 28] in an effort to reduce foot pain. Previous studies have reported that decreased quadriceps strength can lead to increased plantar fascia load and decreased control of pronation of the foot, [26, 29] thereby increasing foot pain. Further prospective studies are necessary to elucidate the results of PF patients in this study.

In the PF patients in this study, the reaction time of the hamstring and quadriceps muscles was delayed, whereas the reaction time of the GCM muscle was rapid compared to those of the control group. We believe that these results may be attributable to joint stabilization strategies in the lower extremity. Muscle reaction can be defined as the ability of the muscle to maintain joint stability while performing a functional task [30,31]; thus, rapid muscle reaction time is an important factor for increased joint stability [31, 32]. The quadriceps, hamstring, and GCM muscles all contribute to the stability of the knee joint. Lloyd and Buchanan reported that the co-contraction of the quadriceps and hamstring muscles directly supports the valgus and varus moments at the knee joint [33]. The valgus and varus moments of the knee joint can impact foot pronation and supination, respectively, [34-36] which may increase plantar fascia stress owing to increased pressure in the forefoot and the hindfoot [20]. In PF patients in this study, the hamstring and quadriceps muscles showed a delayed reaction time, with greater pressure in the forefoot and hindfoot, and hindfoot valgus on pedobarography, despite having normal feet on plain radiographs, compared to those in the control group. Hence, functional abnormalities of the hamstring and quadriceps muscles may contribute to increased pressure in the forefoot and hindfoot. In particular, the reaction time of the GCM muscle showed a significant negative correlation with the strength and reaction time of the quadriceps muscles in this study. Therefore, we believe that the GCM muscle may respond rapidly to support the valgus/varus moments in patients with PF whose hamstring and quadriceps muscles have a delayed reaction time. Previous studies have also reported that the GCM muscle plays an important role in supporting the frontal plane knee alignment (valgus/varus moments) at the knee joint [33, 37]. Kvist and Gillquist, [38]

Table 2 Comparison of muscle strength and acceleration time in both ankles between the patients with plantar fasciitis and normal controls

\begin{tabular}{|c|c|c|c|c|c|c|}
\hline & \multicolumn{3}{|l|}{ Affected ankles } & \multicolumn{3}{|l|}{ Unaffected ankles } \\
\hline & PF patients group & Normal control group & $\overline{p \text {-value }}$ & PF patients group & Normal control group & $p$-value \\
\hline GCM strength & $30 \pm 11.4$ & $41 \pm 14.4$ & 0.278 & $37 \pm 10.9$ & $41 \pm 11.5$ & 0.633 \\
\hline Quadriceps strength & $115 \pm 34.7$ & $144 \pm 26.1$ & $0.005^{a}$ & $126 \pm 34.8$ & $141 \pm 21.9$ & 0.110 \\
\hline Hamstring strength & $61 \pm 20.4$ & $68 \pm 12.7$ & 0.182 & $74 \pm 16.9$ & $77 \pm 8.2$ & 0.370 \\
\hline GCM AT & $30 \pm 11.4$ & $41 \pm 14.4$ & $0.009^{a}$ & $37 \pm 10.9$ & $41 \pm 11.5$ & 0.278 \\
\hline Quadriceps AT & $64 \pm 25.2$ & $48 \pm 14.4$ & $0.012^{a}$ & $54 \pm 25.2$ & $51 \pm 14$ & 0.652 \\
\hline Hamstring AT & $77 \pm 21.9$ & $56 \pm 15.6$ & $0.001^{a}$ & $60 \pm 13.7$ & $58 \pm 17.7$ & 0.629 \\
\hline Forefoot pressure & $70 \pm 27.7$ & $46 \pm 15.7$ & $0.001^{a}$ & $52 \pm 18.7$ & $46 \pm 15.7$ & 0.277 \\
\hline Hindfoot pressure & $65 \pm 22.8$ & $36 \pm 15.2$ & $0.000^{a}$ & $44 \pm 18.6$ & $36 \pm 15.2$ & 0.115 \\
\hline Foot posture ( $W$ index) & $0.2 \pm 0.3$ & $0 \pm 0.2$ & $0.039^{a}$ & $-0.1 \pm 0.3$ & $0 \pm 0.2$ & 0.861 \\
\hline
\end{tabular}

Abbreviations: PF plantar fasciitis, GCM gastrocnemius, $A T$ acceleration time, $V V$ index valgus/varus index

Note: The values are expressed as mean \pm standard deviation

Measurement units for muscle strength and muscle reaction time were $\mathrm{Nm} \mathrm{kg}^{-1} \times 100$ and milliseconds, respectively

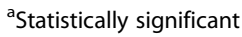


Table 3 Correlations between the muscle strength and muscle reaction time

\begin{tabular}{|c|c|c|c|c|c|}
\hline \multirow[t]{2}{*}{ Parameters } & & \multicolumn{2}{|l|}{ Affected ankles } & \multicolumn{2}{|c|}{ Unaffected ankles } \\
\hline & & GCM strength & GCM AT & GCM strength & GCM AT \\
\hline \multirow[t]{2}{*}{ Quadriceps strength } & PCC (r) & .289 & -.598 & .277 & -252 \\
\hline & $p$-value & .204 & $.004^{a}$ & .225 & .271 \\
\hline \multirow[t]{2}{*}{ Hamstring strength } & PCC (r) & .634 & -.371 & .632 & -.113 \\
\hline & $p$-value & $.002^{a}$ & .098 & $.002^{a}$ & .627 \\
\hline \multirow[t]{2}{*}{ Quadriceps AT } & $P C C(r)$ & -.533 & -.472 & -.189 & .080 \\
\hline & $p$-value & $.013^{a}$ & $.031^{\mathrm{a}}$ & .412 & .732 \\
\hline \multirow[t]{2}{*}{ Hamstring AT } & PCC (r) & -.357 & .212 & .213 & -.351 \\
\hline & $p$-value & .112 & .356 & .354 & .119 \\
\hline
\end{tabular}

Abbreviations: PCC Pearson's correlation coefficient, GCM gastrocnemius, AT acceleration time

${ }^{\text {a }}$ Statistically significant

and Meunier et al. [39] reported that the GCM muscle is neurologically connected to the quadriceps muscle. Consequently, we believe that the reaction time of the hamstring and quadriceps muscles should be assessed and improved, as necessary, in patients with PF.

There were several limitations to the present study. First, the strength of gluteal and hip muscles, such as the hip abductors, was not evaluated in this study, even though previous studies $[5,10,40]$ have reported that hip muscle strength is closely related to foot pain. Second, post rehabilitation results were not included in the correlation analysis. To confirm that the functional abnormalities of the hamstring and quadriceps muscles shown in our results represent a definite etiology of PF in patients without tightness of the GCM and hamstring muscles, further evaluations of the quadriceps and hamstring muscles should be done following rehabilitation. In addition, further studies on how the performance of the hamstrings, quadriceps, and GCM muscles of patients who were excluded from this study will contribute to PF will also improve our understanding of PF in various patients. Finally, intrinsic foot muscle function was not assessed. Intrinsic foot muscles play an important role in the stability of the normal foot and in lower extremity function; thus, impairment of these muscles may affect lower extremity biomechanics, which may result in changes in the function of the quadriceps, hamstring, and GCM muscles.

\section{Conclusions}

This study revealed the presence of weakness and delayed reaction time of the hamstring and quadriceps muscles, and a rapid reaction time of the GCM muscle in patients with PF. Clinicians and therapists should aim to evaluate and improve the functionality of these muscles in patients with PF.

\section{Abbreviations}

PF: Plantar fasciitis; GCM: Gastrocnemius; AT: Acceleration time; MFF: Medial forefoot; LFF: Lateral forefoot; MMF: Medial midfoot; LMF: Lateral midfoot; W index: Valgus index
Acknowledgements

Not applicable.

Authors' contributions

$J H L$ and WYJ collected and analyzed patient clinical data. JHL and HWJ interpreted the data and were major contributors in writing of the manuscript. WYJ revised the final manuscript. All authors have read and approved the final manuscript.

\section{Funding}

This work was supported by the Technology Development Program of the Ministry of SMEs and Startups (MSS, Korea, No. S2828229) and Institute for Information \& Communications Technology Promotion (IITP) grant funded by the Korea government (MSIT) (No.2019-0-00418, 3D Printing for Family Health Based on Real-life Smart Insoles Manufactured and Consistent System Development).

\section{Availability of data and materials}

The datasets used and/or analyzed in this study are available from the corresponding author upon reasonable request.

\section{Ethics approval and consent to participate}

The study protocol was approved by Korea University Anam Hospital Institutional Review Board (No: 2018AN0168). All study participants provided written informed consent before being enrolled in this study.

Consent for publication

Not applicable.

\section{Competing interests}

The authors declare that they have no competing interests.

\section{Author details}

'Department of Sports Medical Center, Korea University College of Medicine, Anam Hospital, Seoul, Republic of Korea. ${ }^{2}$ Department of Pediatrics, Kyung Hee University Medical Center, Seoul, South Korea. ${ }^{3}$ Department of Orthopedic Surgery, College of Medicine, Korea University, 73, Inchon-ro, Seongbuk-gu, Seoul 02841, Republic of Korea.

Received: 30 July 2020 Accepted: 23 October 2020

Published online: 05 November 2020

\section{References}

1. Huguenin L, Brukner PD, McCrory P, Smith P, Wajswelner H, Bennell K. Effect of dry needling of gluteal muscles on straight leg raise: a randomised, placebo controlled, double blind trial. Br J Sports Med. 2005:39:84-90.

2. Waclawski ER, Beach J, Milne A, Yacyshyn E, Dryden DM. Systematic review: plantar fasciitis and prolonged weight bearing. Occup Med (Lond). 2015;65: 97-106

3. Periyasamy $R$, Anand $S, A$ mmini $A C$. The effect of aging on the hardness of foot sole skin: a preliminary study. Foot (Edinb). 2012;22:95-9. 
4. Chen DW, Li B, Aubeeluck A, Yang YF, Huang YG, Zhou JQ, et al. Anatomy and biomechanical properties of the plantar aponeurosis: a cadaveric study. PLoS One. 2014;9:e84347.

5. Lee $J H$, Park $J H$, Jang WY. The effects of hip strengthening exercises in a patient with plantar fasciitis: A case report. Medicine (Baltimore). 2019;98: e16258.

6. Martin RL, Davenport TE, Reischl SF, McPoil TG, Matheson JW, Wukich DK, et al. Heel pain-plantar fasciitis: revision 2014. J Orthop Sports Phys Ther. 2014;44:A1-33.

7. Labovitz JM, Yu J, Kim C. The role of hamstring tightness in plantar fasciitis Foot Ankle Spec. 2011:4:141-4.

8. Pascual HJ. The effect of the gastrocnemius on the plantar fascia. Foot Ankle Clin. 2014;19:701-18.

9. Harty J, Soffe K, O'Toole G, Stephens MM. The role of hamstring tightness in plantar fasciitis. Foot Ankle Int. 2005;26:1089-92.

10. Backstrom K, Moore A. Plantar fasciitis. Phys Ther Case Rep. 2000;3:154-62.

11. Huffer D, Hing W, Newton R, Clair M. Strength training for plantar fasciitis and the intrinsic foot musculature: a systematic review. Phys Ther Sport. 2017;24:44-52

12. Malfait B, Dingenen B, Smeets A, Staes F, Pataky T, Robinson MA, et al. Knee and hip joint kinematics predict quadriceps and hamstrings neuromuscular activation patterns in drop jump landings. PLoS One. 2016;11:e0153737.

13. Shultz SJ, Nguyen AD, Leonard MD, Schmitz RJ. Thigh strength and activation as predictors of knee biomechanics during a drop jump task. Med Sci Sports Exerc. 2009:41:857-66.

14. Thomas AC, McLean SG, Palmieri-Smith RM. Quadriceps and hamstrings fatigue alters hip and knee mechanics. J Appl Biomech. 2010;26:159-70.

15. Ward SH, Blackburn JT, Padua DA, Stanley LE, Harkey MS, Luc-Harkey BA, et al. Quadriceps neuromuscular function and jump-landing sagittal-plane knee biomechanics after anterior cruciate ligament reconstruction. J Athl Train. 2018:53:135-43.

16. Li L, Landin D, Grodesky J, Myers J. The function of gastrocnemius as a knee flexor at selected knee and ankle angles. J Electromyogr Kinesiol. 2002;12:385-90.

17. Chen WL, Su FC, Chou YL. Significance of acceleration period in a dynamic strength testing study. J Orthop Sports Phys Ther. 1994;19:324-30.

18. Lee JH, Han SB, Park JH, Choi JH, Suh DK, Jang KM. Impaired neuromuscular control up to postoperative 1 year in operated and nonoperated knees after anterior cruciate ligament reconstruction. Medicine (Baltimore). 2019;98:e15124.

19. Lee JH, Lee SH, Choi GW, Jung HW, Jang WY. Individuals with recurrent ankle sprain demonstrate postural instability and neuromuscular contro deficits in unaffected side. Knee Surg Sports Traumatol Arthrosc. 2018. https://doi.org/10.1007/s00167-018-5190-1.

20. Becerro-de-Bengoa-Vallejo R, Losa-Iglesias ME, Rodriguez-Sanz D. Static and dynamic plantar pressures in children with and without sever disease: a case-control study. Phys Ther. 2014;94:818-26.

21. Lee KM, Chung CY, Park MS, Lee $\mathrm{SH}$, Cho JH, Choi $I \mathrm{H}$. Reliability and validity of radiographic measurements in hindfoot varus and valgus. J Bone Joint Surg Am. 2010;92:2319-27.

22. Lee $\mathrm{H}$, Lee $\mathrm{SH}$, Jung HW, Jang WY. Modified Brostrom procedure in patients with chronic ankle instability is superior to conservative treatment in terms of muscle endurance and postural stability. Knee Surg Sports Traumatol Arthrosc. 2019. https://doi.org/10.1007/s00167-019-05582-4

23. Noyes FR, Barber SD, Mooar LA. A rationale for assessing sports activity levels and limitations in knee disorders. Clin Orthop Relat Res. 1989;246:23849.

24. Mann RA. RE: The effect on ankle dorsiflexion of gastrocsoleus recession Pinney SJ, et al., foot ankle Int. 2002;23:26-29. Foot Ankle Int. 2003;24:726-7 author reply 7-8.

25. Lunnen JD, Yack J, LeVeau BF. Relationship between muscle length, muscle activity, and torque of the hamstring muscles. Phys Ther. 1981;61:190-5.

26. Bolgla LA, Malone TR. Plantar fasciitis and the windlass mechanism: a biomechanical link to clinical practice. J Athl Train. 2004;39:77-82.

27. Farhan H, Moreno-Duarte I, Latronico N, Zafonte R, Eikermann M. Acquired muscle weakness in the surgical intensive care unit: nosology, epidemiology, diagnosis, and prevention. Anesthesiology. 2016;124:207-34.

28. Fredericson M, Cookingham CL, Chaudhari AM, Dowdell BC, Oestreicher N, Sahrmann SA. Hip abductor weakness in distance runners with iliotibial band syndrome. Clin J Sport Med. 2000;10:169-75.

29. Sahrmann, S. Diagnosis and Treatment of Movement Impairment Syndromes-E-Book. Elsevier Health Sciences; 2013.
30. Linford CW, Hopkins JT, Schulthies SS, Freland B, Draper DO, Hunter I. Effects of neuromuscular training on the reaction time and electromechanical delay of the peroneus longus muscle. Arch Phys Med Rehabil. 2006;87:395-401.

31. Thain PK, Bleakley CM, Mitchell AC. Muscle reaction time during a simulated lateral ankle sprain after wet-ice application or cold-water immersion. J Athl Train. 2015;50:697-703.

32. Arnold P, Vantieghem S, Gorus E, Lauwers E, Fierens Y, Pool-Goudzwaard A, et al. Age-related differences in muscle recruitment and reaction-time performance. Exp Gerontol. 2015;70:125-30.

33. Lloyd DG, Buchanan TS. Strategies of muscular support of varus and valgus isometric loads at the human knee. J Biomech. 2001;34:1257-67.

34. Norton AA, Callaghan JJ, Amendola A, Phisitkul P, Wongsak S, Liu SS, et al. Correlation of knee and hindfoot deformities in advanced knee OA: compensatory hindfoot alignment and where it occurs. Clin Orthop Relat Res. 2015;473:166-74.

35. Ohi H, lijima H, Aoyama T, Kaneda E, Ohi K, Abe K. Association of frontal plane knee alignment with foot posture in patients with medial knee osteoarthritis. BMC Musculoskelet Disord. 2017;18:246.

36. Wyndow N, De Jong A, Rial K, Tucker K, Collins N, Vicenzino B, et al. The relationship of foot and ankle mobility to the frontal plane projection angle in asymptomatic adults. J Foot Ankle Res. 2016;9:3.

37. Morgan KD, Donnelly CJ, Reinbolt JA. Elevated gastrocnemius forces compensate for decreased hamstrings forces during the weight-acceptance phase of single-leg jump landing: implications for anterior cruciate ligament injury risk. J Biomech. 2014;47:3295-302.

38. Kvist J, Gillquist J. Anterior positioning of tibia during motion after anterior cruciate ligament injury. Med Sci Sports Exerc. 2001;33:1063-72.

39. Meunier S, Pierrot-Deseilligny E, Simonetta M. Pattern of monosynaptic heteronymous la connections in the human lower limb. Exp Brain Res. 1993; 96:534-44.

40. Kamonseki DH, Goncalves GA, Yi LC, Junior IL. Effect of stretching with and without muscle strengthening exercises for the foot and hip in patients with plantar fasciitis: a randomized controlled single-blind clinical trial. Man Ther. 2016;23:76-82

\section{Publisher's Note}

Springer Nature remains neutral with regard to jurisdictional claims in published maps and institutional affiliations.

Ready to submit your research? Choose BMC and benefit from:

- fast, convenient online submission

- thorough peer review by experienced researchers in your field

- rapid publication on acceptance

- support for research data, including large and complex data types

- gold Open Access which fosters wider collaboration and increased citations

- maximum visibility for your research: over $100 \mathrm{M}$ website views per year

At BMC, research is always in progress.

Learn more biomedcentral.com/submissions 